\title{
Detecção do rotavírus humano em crianças hospitalizadas com quadros diarréicos em Salvador, Bahia, Brasil
}

\section{Detection of human rotavirus in children with diarrhea episodes in Salvador, Bahia, Brazil}

\author{
GÚBIO SOARES CAMPOS ${ }^{1}$, SÍLVIA INESS SARDI ${ }^{2}$, ALINE SANTOS SAMPAIO ${ }^{3}$, \\ VIVIANE BRANDÃO BANDEIRA DEMELLO ${ }^{3}$ \\ Farmacêutico Bioquímico. Pesquisador. Instituto de Ciências da Saúde. UFBA \\ ${ }^{2}$ Professora de Microbiologia. Instituto de Ciências da Saúde. UFBA \\ ${ }^{3}$ Bolsista PIBIC-CNPq. Instituto de Ciências da Saúde. UFBA
}

\section{Resumo}

A diarréia aguda infantil é um importante problema na saúde pública e os rotavírus são responsáveis por cerca de 20 a $40 \%$ dos casos de diarréia severa e desidratação em crianças de 0 a 5 anos de idade. Foram analisadas fezes de crianças de 0 a 4 anos que estiveram hospitalizadas com diarréia no periodo de outubro de 1998 a dezembro de 1999, em Salvador. As amostras foram analisadas por técnicas de ELISA e SDS-PAGE. Das 217 amostras testadas, 76 (35\%) foram positivas para rotavirus, 127 (58,5\%) foram negativas e 14 (6,5\%) divergiram quanto ao resultado. Através da análise das amostras positivas por SDS-PAGE, pôde-se identificar os rotavirus pertencentes ao grupo A, classificando-os em eletroferotipos curtos, comuns ao subgrupo I, e longos, comuns ao subgrupo II.

\section{Palavras-chave}

Rotavírus humano, diagnóstico, eletroferotipos

Dr. Gúbio Soares Campos

Laboratório de Virologia

Departamento de Biointeração

Instituto de Ciências da Saúde

Universidade Federal da Bahia

Av. Reitor Miguel Calmon s/n Vale do Canela

40.110-100 - Salvador, Bahia, Brasil

e-mail: labviro@svn.com.br 


\section{Introdução}

Os rotavirus são os principais agentes virais causadores de diarréia aguda infantil. Eles são responsáveis por quase 125 mil casos de diarréia por ano, representando $20 \%$ a $40 \%$ das hospitalizações por diarréia em crianças menores de cinco anos (RAMACHANDRAN, 1998).

Os rotavírus são vírus pertencentes à família Reoviridae. A denominação rotavirus deve-se à sua semelhança com uma roda de carroça ao microscópio eletrônico (PARASHAR, 1998). Têm tamanho de $70 \mathrm{~nm}$ de diâmetro, o genoma viral é formado por onze segmentos de RNA de fita dupla responsáveis pela codificação de sete proteínas estruturais e seis outras não estruturais (FIELDS, 2001). São vírus não envelopados que possuem dupla cápside protéica icosaédrica, sendo a externa formada pelas proteínas VP7 e VP4 e a interna formada pela VP6. Esta última permite a classificação dos rotavirus em sete grupos designados de A a G, sendo os do grupo A responsáveis pela quase totalidade das infecções. A proteína VP7 é glicosilada e principal constituinte do capsídeo externo; ela induz a produção de anticorpos neutralizantes. A proteína VP4 está associada às diversas funções biológicas do vírus. Estas duas proteínas classificam os rotavirus em genótipos especificados em tipos G (VP7) e tipos P (VP4).

$\mathrm{O}$ rotavirus produz uma gastroenterite aguda transmitida através da via fecal-oral, pois o virus se instala nos enterócitos maduros do intestino delgado. Há lesão direta da borda em escova, causando diarréia aguda secretória, com má absorção de nutrientes, perda de fluidos e eletrólitos, que muito freqüentemente leva à desidratação. Podem-se apresentar vômitos, febre, distensão abdominal e sintomas respiratórios associados (TEIXEIRA et al., 1998). Muitos estudos indicam que aproximadamente $70 \%$ das infecções sintomáticas por rotavirus ocorrem entre os 6 e os 24 meses de idade (VERONESI, 1996).

No Brasil, os primeiros achados ocorreram em Belém, Pará, em 1976 e, desde então, já foram diagnosticados rotavírus em todo o território nacional, ressaltando a relevância que assumem esses agentes na gênese das diarréias agudas infantis (LINHARES et al., 1993; SANTOS; GOUVEA, 1997).

Os estudos feitos com pacientes hospitalizados detectaram que os tipos de rotavirus encontrados nesses pacientes refletem os mesmos que apresentam os indivíduos infectados na comunidade e que não recorreram à hospitalização (VERONESI, 1996).

Nosso trabalho teve o objetivo de iniciar um estudo epidemiológico para observar a freqüência dos rotavirus como causadores de diarréia em crianças e caracterizar o padrão eletroforético do rotavirus encontrado.

\section{Materiais e métodos}

\section{Coleta de amostras}

A coleta de amostras foi realizada no período de outubro de 1998 a dezembro de 1999. Foram coletadas amostras de fezes de crianças de 0 a 4 anos $(n=217)$, com quadro clínico diarréico, hospitalizadas na Unidade Metabólica Fima Lifshtz do Centro Pediátrico Prof. Hosannah de Oliveira e no Hospital Martagão Gesteira, Salvador, Bahia.

As fezes foram congeladas a $-20^{\circ} \mathrm{C}$ até seu processamento.

\section{Teste imunoenzimático-ELISA}

As fezes foram, primeiramente, submetidas ao teste de ELISA TestPack ABBOT, kit de uso comercial, segundo as instruções e a interpretação dos resultados do fabricante.

\section{Extração de RNA}

As fezes foram diluídas em solução salina buferada (PBS) 20\% (v/v) e centrifugadas a $3.000 \mathrm{rpm}$ durante 10 minutos a $4^{\circ} \mathrm{C}$.

O sobrenadante foi tratado com $10 \%$ de uma solução de SDS, $10 \%$ e 5\% de uma solução de EDTA $100 \mathrm{mM}$ e aquecido a $56^{\circ} \mathrm{C}$ durante 20 minutos. A extração de RNA viral foi feita com uma solução de fenol-clorofórmio adicionada em volume igual ao sobrenadante 
das fezes tratadas e posteriormente centrifugada a $12.000 \mathrm{~g}$ durante 10 minutos, coletando-se a fração aquosa. A este sobrenadante foram adicionados $100 \mu \mathrm{l}$ de acetato de $\mathrm{Na} 3 \mathrm{M}$ e $1 \mathrm{ml}$ de etanol absoluto, sendo deixado por toda a noite a $-20^{\circ} \mathrm{C}$. Posteriormente, foi centrifugado a $12.000 \mathrm{~g}$ por 15 minutos a $4^{\circ} \mathrm{C}$, descartado o sobrenadante, e o precipitado final foi ressuspenso em um buffer desnaturalizante (Tris/ $\mathrm{HCl}, \mathrm{pH}$ 6,8, $125 \mathrm{mM}$, SDS 4\%, mercapto etanol 3\%, glicerol 20\%, azul de bromofenol 20\%) para posterior análise por SDS-PAGE.

\section{Eletroforese em gel de poliacrilamida (SDS-PAGE)}

O RNA extraído foi submetido a eletroforese em gel de poliacrilamida 7.5\% (SDSPAGE) a $40 \mathrm{~V}$, durante a noite, e posteriormente submetido a uma solução fixadora (etanol $10 \%$-ácido acético $0,5 \%$ ) e logo corado com uma solução de $\mathrm{AgNO}_{3} 7 \mathrm{mM}$. Isto permitiu a visualização das bandas correspondentes aos segmentos de RNA viral.

\section{Resultados e discussão}

Das 217 amostras processadas pelos métodos ELISA e SDS-PAGE, 76 foram positivas para rotavirus (35\%) e 127 (58,5\%) foram negativas. Apenas 14 amostras (6,5\%) mostraram resultados divergentes entre os dois métodos, 12 foram positivas apenas por ELISA e duas positivas por SDS-PAGE (TAB. 1 e FIG. 1).

\section{TABELA 1}

Detecção de rotavírus por ELISA e SDS-PAGE em amostras fecais

\begin{tabular}{lcccc}
\hline & Positivo & Negativo & Divergente & Total \\
\hline No de amostras & 76 & 127 & 14 & 217 \\
Porcentagem (\%) & 35 & 58,5 & 6,5 & 100 \\
\hline
\end{tabular}

Na FIG. 2, observa-se que houve uma concentração de resultados nos meses de agosto e setembro, coincidindo com o período de maior número de amostras analisadas. Em 5 amostras não foi possivel identificar o mês em que ocorreu o episódio diarréico.

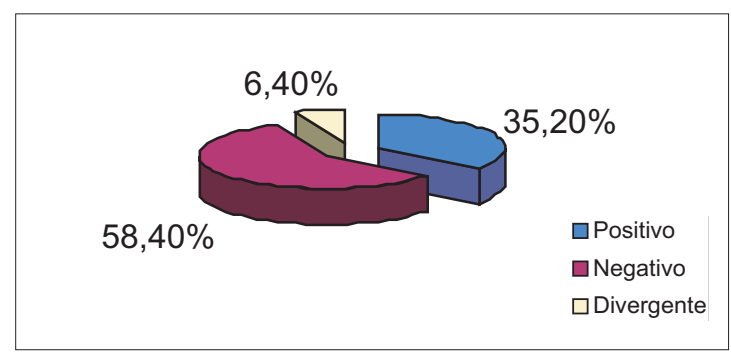

FIGURA 1 - Detecção de rotavirus em amostras de fezes diarréicas em Salvador, BA, no periodo de outubro de 1998 a dezembro de 1999

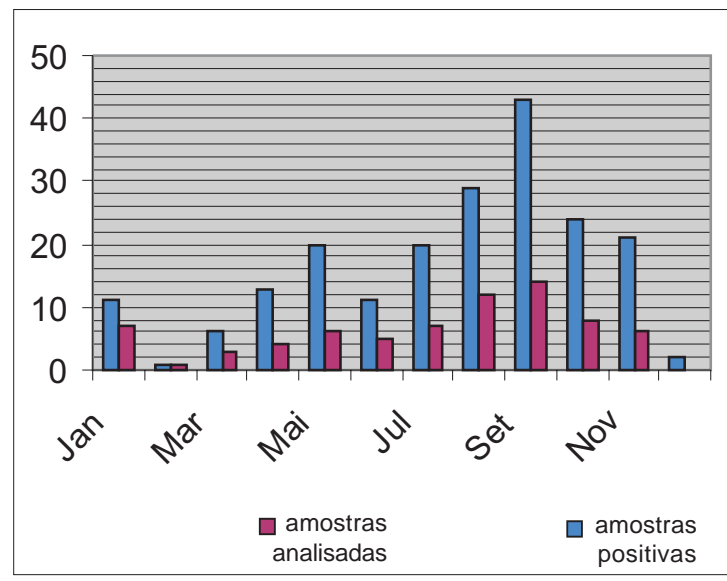

FIGURA 2 - Casos positivos de diarréia por rotavirus durante o periodo de um ano em Salvador, Bahia

Na FIG. 3, mostra-se o padrão eletroforético da cepa protótipo e de algumas das amostras positivas. $O$ vírus padrão cepa SA11 do grupo A, encontra-se na $8^{\text {a }}$ linha. Observa-se que o padrão eletroforético consta de 11 bandas ou segmentos de RNA, agrupados em 4 blocos segundo a disposição de 4 bandas, 2 bandas, 3 bandas e 2 bandas, agrupamento que distingue o grupo A (GOUVEA; SANTOS, 1998). Ao analisar as amostras por SDS-PAGE, ficou demonstrado que 27 apresentaram perfil eletroferotípico curto e 51 apresentaram o perfil longo. Isso ocorre porque o $11^{\circ}$ segmento de RNA migra mais lentamente do que o usual e fica localizado entre o $9^{\circ}$ e o $10^{\circ}$ segmentos, caracterizando um padrão curto, comum à maioria dos rotavírus do subgrupo I. Da mesma forma, o eletroferotipo longo é caracteristico da maioria dos rotavírus do subgrupo II. 


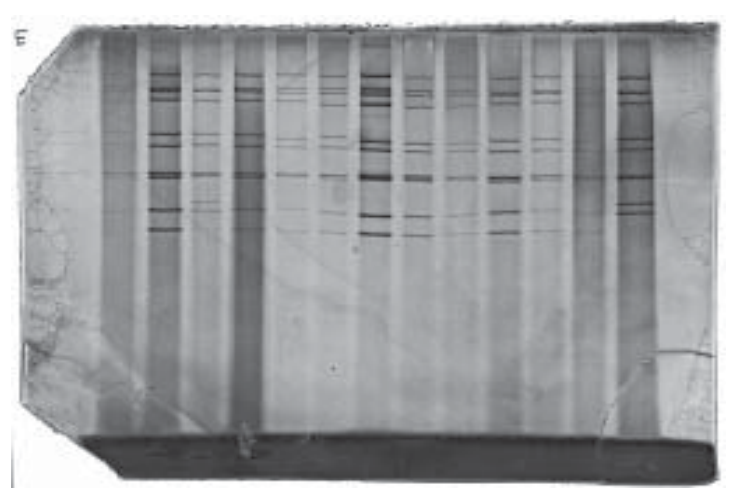

FIGURA 3 - Corrida em gel de poliacrilamida 7\% (SDS. PAGE) do RNA viral.

$\mathrm{O}$ virus protótipo SA11 do grupo A de rotavirus pode ser visualizado na $8^{a}$ coluna. Nas $3^{a}$ e $13^{a}$ colunas, observam-se padrões eletroforéticos curtos e, nas demais colunas, padrões longos. Todas as amostras revelaram a presença de grupo A de rotavirus.

Neste trabalho, contatou-se que a freqüência de diarréia por infecção a rotavírus em crianças hospitalizadas na região de Salvador foi de $35 \%$, achado semelhante ao encontrado na literatura (20\% e $40 \%)$ para diferentes regiões do pais (GOUVEA; SANTOS, 1998; SPECTER; HADINKA; YOUNG, 2000), assim como uma maior concentração de casos positivos nos meses de inverno, apesar de existirem casos positivos durante todo o ano.

O teste utilizado (ELISA) é uma técnica de alta sensibilidade e especificidade para a detecção de rotavirus. $O$ kit comercial utilizado neste trabalho demonstrou correspondência com os dados obtidos no SDS-PAGE. Das 217 amostras testadas, apenas 10 foram negativas por SDSPAGE e positivas por ELISA. Isso pode ser explicado pelo fato de que a técnica por SDS-PAGE precisa de uma carga viral maior para a detecção do RNA viral ou de que a degradação do RNA pela ação enzimática das fezes dificulta sua detecção. Embora o ELISA seja uma técnica de alta sensibilidade, não fornece informação sobre o tipo de rotavirus envolvido na infecção. Por isso o SDS-PAGE continua sendo uma ferramenta importante na epidemiologia molecular das rotaviroses. É uma técnica que oferece a vantagem de ser simples e de fácil implementação em laboratórios de rotina diagnóstica. Neste estudo, o SDS-PAGE permitiu a detecção de eletroferotipos longo e curto, demonstrando a presença de subgrupos I e II, respectivamente, com uma freqüencia que foi semellante à encontrada na literatura (GOUVEA; SANTOS, 1998; SPECTER; HADINKA; YOUNG, 2000). Por outra parte, não foram detectadas infecções mistas, visto que todas as amostras avaliadas não exibiram mais de 11 segmentos de RNA viral.

\section{Conclusões}

Deste estudo, podemos concluir que o rotavirus é um agente etiológico de importância nas diarréias em crianças hospitalizadas na região de Salvador, demonstradas a sua freqüência e a presença de eletroferotipos diferentes. Este achado deve ser tomado em consideração nos diagnósticos clínico-laboratoriais ante a apresentação de quadros clínicos de diarréias infantis.

Este estudo terá continuidade, visando a identificação nas amostras dos genótipos mais prevalentes na região. Estes dados serão um importante aporte na epidemiologia molecular das diarréias causadas por rotavírus, já que se prevê, no futuro, uma possivel aplicação de vacinas contra essa infecção.

\section{Agradecimentos}

À FAPESB-SEPLANTEC, pelo apoio ao Laboratório de Virologia, ICS-UFBA. Ao CNPq, pela bolsa PIBIC. À Unidade Metabólica Fima Lifshitz do Centro Pediátrico Professor Hosannah de Oliveira e ao Hospital Martagão Gesteira. 


\begin{abstract}
Acute infantile diarrhea is an important problem in public healthcare and Rotaviruses are responsible for about 20-40\% of the cases of severe dehydrating diarrhea in children at 0-5 years old. In this work, we have analyzed diarrheic feces from children at 0-4 years old hospitalized between October 1998 and December 1999, in Salvador, Bahia, Brazil. In order to detect rotavirus, the samples were analyzed by ELISA (Test-Pack Abbot) and SDS-PAGE tests. The results demonstrated that from the 217 samples tested, 76 (35\%) were positive, 127 (58,5\%) were negative and 14 (6,5\%) diverged in both tests. The positive samples analyzed by SDS-PAGE test revealed the group A rotavirus and they were classified as short eletropherotypes (Subgroup I) and long eletropherotypes (Subgroup II).
\end{abstract}

\title{
Key words
}

Rotavirus, diagnoses, eletropherotypes

\section{Referências}

FIELDS, B. Virology. 4th ed. Philadelphia: Lippincott Williams \& Wilkins, 2001.

GOUVEA, V.; SANTOS, N. Detecção de rotavirus atipicos em crianças com diarréia no Rio de Janeiro. Newslab, n. 32 , p. 15-24, 1998.

LINHARES, A. et al. Rotavirus serotypes and electrophoretypes among children attending three pediatric hospitals in Belém, Brazil. J. Trop. Ped., n. 39, p. 137-141, 1993.

PARASHAR, U. D. Rotavirus. Emerging Infections Diseases, v. 4, p. 561-567, 1998.
RAMASHANDRAN, M. Detection and characterization of novels rotavirus strains in the United States. Journal of Clinical Microbiology, v. 36, n. 11, p. 3223-3229, 1998.

SANTOS, N.; GOUVEA, V. Infecção por rotavirus: aspectos atuais. Journal of Brazilian Pathology, v. 33, n. 2, p. 94 102, 1997.

SPECTER, S.; HADINKA, R. L.; YOUNG, S. A. Clinical virology manual. 3rd ed. New York: ASM Press, 2000.

TEIXEIRA, J. M. S. et al. Human group C rotavirus in children with diarrhea in the Federal District, Brazil. Brazilian Journal of Medical and Biological Research, n. 31, p. 1397-1403, 1998.

VERONESI, R. Tratado de infectologia. São Paulo: Ateneu, 1996. 